\title{
Prevalence and duration of breast milk feeding in very preterm infants: A 3-year follow-up study and a systematic literature review
}

\author{
Carina Rodrigues $^{1}$ (D) | Raquel Teixeira ${ }^{1}$ (D) | Maria João Fonseca ${ }^{1,2}$ (D) | \\ Jennifer Zeitlin ${ }^{3}$ (D) | Henrique Barros ${ }^{1,2}$ (D) | on behalf of the Portuguese EPICE (Effective \\ Perinatal Intensive Care in Europe) Network*
}

\begin{abstract}
${ }^{1}$ EPIUnit-Instituto de Saúde Pública, Universidade do Porto, Porto, Portugal

${ }^{2}$ Departamento de Ciências da Saúde Pública e Forenses e Educação Médica, Faculdade de Medicina, Universidade do Porto, Porto, Portugal

${ }^{3}$ INSERM, Obstetrical, Perinatal and Paediatric Epidemiology Research Team, Centre for Epidemiology and Biostatistics (U1153), Paris-Descartes University, Paris, France
\end{abstract}

\section{Correspondence}

Carina Rodrigues, EPIUnit-Instituto de Saúde Pública, Universidade do Porto, Porto, Portugal.

Email: carina.rodrigues@ispup.up.pt

\section{Funding information}

This study was funded by the European Union Seventh Framework Programme (FP7/2007-2013) under grant agreement no. 259882 . This study was also funded by FEDER through the Operational Programme Competitiveness and Internationalization and national funding from the Foundation for Science and Technology-FCT (Portuguese Ministry of Science, Technology and Higher Education), under the Unidade de Investigação em Epidemiologia-Instituto de Saúde Pública da Universidade do Porto (EPIUnit) (POCI-01-0145-FEDER-006862; Ref.UID/DTP/04750/2013); the PhD Grant SFRH/BD/111794/2015 (Carina Rodrigues) and the individual grant SFRH/ BSAB/113778/2015 (Henrique Barros), co-funded by the FCT and the POCH/FSE Program.

\begin{abstract}
Background: The World Health Organization recommends exclusive breast milk feeding until 6 months and continuing up to 2 years of age; little is known about whether very preterm infants are fed in accordance with these recommendations. We aimed to describe the prevalence and duration of breast milk feeding in very preterm children and to systematically review internationally published data.

Methods: We evaluated breast milk feeding initiation and duration in very preterm children born in 2 Portuguese regions (2011-2012) enrolled in the EPICE cohort and followed-up to the age of $3(n=466)$. We searched PubMed ${ }^{\circledR}$ from inception to January 2017 to identify original studies reporting the prevalence and/or duration of breast milk feeding in very preterm children.

Results: $\mathbf{9 1 . 0 \%}$ of children received some breast milk feeding and $65.3 \%$ were exclusively breast fed with a median duration of 2 months for exclusive and 3 months for any breast milk; only $9.9 \%$ received exclusive breast milk for at least 6 months, $10.2 \%$ received any breast milk for 12 months or more, and $2.0 \%$ for up to 24 months. The literature review identified few studies on feeding after hospital discharge $(n=9)$; these also reported a low prevalence of exclusive breast milk feeding at 6 months (1.0\% to $27.0 \%$ ) and of any breast milk at 12 months (8.0\% to $12.0 \%)$.

Conclusions: The duration of breast milk feeding among Portuguese very preterm infants was shorter than recommended. However, this appears to be common globally. Research is needed to inform strategies to promote continued breast milk feeding.
\end{abstract}

\section{KEYWORDS}

breast feeding, breast milk, EPICE project, very preterm infants 


\section{1 | INTRODUCTION}

There is a general recommendation to provide exclusive breast milk feeding during the first 6 months of life to both full-term and preterm infants, and to continue up to 2 years or longer with complementary foods. ${ }^{1,2}$ There is evidence regarding the health benefits of breast milk feeding for very preterm infants (born at $<32$ weeks of gestation), namely, in decreasing multiple neonatal morbidity conditions related to prematurity, such as infections and necrotizing enterocolitis, and also, in the improvement of neurodevelopmental outcomes. ${ }^{2,3}$

Despite these benefits, a low prevalence of breast milk feeding is still described and seems common in very preterm children. ${ }^{4-6}$ Most research has focused on breast milk feeding in hospital or at discharge home from hospital with fewer studies able to describe the full duration of breast milk feeding. ${ }^{6}$ In Portugal, the frequency of breast milk feeding in these children has only been evaluated twice, at discharge in $2003^{4}$ and $15-22$ days after delivery during Neonatal Intensive Care Unit (NICU) stay in 2013, ${ }^{7}$ both studies described the North region. No information is available about the duration of exclusive or any breast milk feeding in Portuguese very preterm infants. Also, in the international context, a systematic evaluation of the prevalence and duration of breast milk feeding in very preterm infants is lacking.

Therefore, this study aimed to describe the frequency and duration of breast milk feeding in Portuguese very preterm infants and to systematically review the published literature on breast milk feeding in very preterm infants, with a focus on studies providing data on the duration of exclusive breast milk for the first 6 months and any breast milk through at least the first year.

\section{2 | METHODS}

\section{1 | Design}

A cohort of very preterm Portuguese children was followed. They were recruited as part of the longitudinal study Effective Perinata Intensive Care in Europe (EPICE) that included all live births between 22 and 31 completed weeks of gestation occurring in 19 regions from 11 European countries, in 2011 to $2012 .^{8}$ The study was approved by the Ethics Committee of the participating hospitals and by the Portuguese Data Protection Authority (authorization 7426/2011). Informed consent was obtained from all parents or legal representative.

\subsection{Setting and sample}

The EPICE study in Portugal involved all the public maternity and neonatal intensive care units (NICUs) from 2 regions [North and Lisbon and Tagus Valley (LTV)] $(n=27)$, along with 3 private units from LTV. In 2011 and 2012, 68.6\% and 66.3\% of all very preterm births in Portugal occurred in these 2 geographical regions, respectively. ${ }^{9}$
The sample included all infants discharged alive from all NICUs whose parents provided informed consent [544 (89.6\%) of 607 eligible participants]. ${ }^{10}$ At the 3 -year follow-up, 2 children had died, 2 children had been adopted and unavailable for further evaluation according to legal rules, 5 parents declined to participate, and 69 were unreachable. Thus, 466 infants remained for this analysis (Figure S1). Participants were compared to 78 non-participants regarding maternal and infant characteristics. Mothers of participants were older, and more frequently born in Portugal, primipara, and breast milk feeding at discharge (Table S1).

\section{3 | Data collection}

Data on maternal and infant characteristics at baseline were abstracted from medical records by local health care professionals using a pretested standardized questionnaire. ${ }^{10}$ We collected data on maternal age, mother's country of birth, parity (primipara vs multipara), twinning, gender, gestational age at birth (weeks), birthweight $(\mathrm{g})$, length of hospitalization (days), type of feeding at discharge, and neighbourhood socio-economic deprivation.

Information on breast milk feeding practices was obtained using a structured questionnaire completed by the parents or legal guardians when the children were 3 years of age (chronological age), using a computer-assisted telephone interview, by trained interviewers. Parents were asked if the child has ever received breast milk feeding, including donor's milk. If the answer was yes then they were asked for how long the child received breast milk exclusively and for how long the child received breast milk feeding combined with formula feeding or with other type of foods and/or beverages.

\subsection{Definition of variables}

Gestational age was based on the best estimate of the obstetrical team, using information from ultrasound measures and last menstrual period. Infants were georeferenced according to their home address using the ArcGIS Online World Geocoding Service and Google Maps. Neighbourhood socio-economic deprivation was assessed using the European Deprivation Index (EDI) that is used to classify small areas according to their level of socio-economic deprivation. The construction of EDI, which was developed for 5 European countries, was fully described elsewhere. ${ }^{11}$ In Portugal, EDI score resulted from the weighted sum of the following standardized variables at census block group level: \% overcrowded households, \% households with no bath or shower, \% household with no indoor flushing, \% households occupied by non-owners, \% women aged 65 or more, \% individuals with low education, \% individuals in low-income occupation, and \% unemployed individuals. The EDI score was categorized in quintiles of increasing deprivation (1-least to 5 -most deprived). ${ }^{12}$

Regarding our outcome of interest, exclusive breast milk feeding was considered when the infant received no food or drinks other than the mother's own milk or donor's milk, regardless of route of administration. Any breast milk feeding was considered 
if the infant received some breast milk, regardless of route of administration, and independently if it was only exclusive or mixed (the addition of formula or other food and/or drink to breast milk). Duration of breast milk feeding was defined as the age of the child, reported in months of chronological age, when the exclusive and any breast milk feeding was stopped completely. Information on any breast milk feeding was obtained for all 466 participants, but 13 did not report the duration period, remaining 453 with information on any breast milk feeding duration. To compute exclusive breast milk feeding, we excluded 22 participants [19 did not report the information and 3 provided unreliable information (duration $\geq 12$ months)], remaining 444 participants for analysis of exclusive breast milk feeding.

\section{5 | Statistical analysis}

Sample characteristics are presented as counts and proportions for all categorical variables, and median and percentile 25 and percentile 75 (p25-p75) for non-normally distributed continuous variables. We compared the maternal and infant characteristics of children receiving exclusive and any breast milk for shorter vs longer durations. Proportions were compared using a chi-square test and non-normally distributed continuous variables with the Kruskal-Wallis test. The duration of exclusive and any breast milk feeding was categorized in 3 groups: (1) never received the type of breast milk considered; (2) between $>0$ and $<4$ months for exclusive and between $>0$ and $<6$ months for any breast milk; (3) and $\geq 4$ months for exclusive and $\geq 6$ months for any breast milk. The cut-off point of 4 months for exclusive breast milk was considered because this is the length of the fully paid maternity leave in Portugal, and so the proportion of children on exclusive breast milk for at least 6 months was very low which would result in lack of statistical power. Also for any breast milk, we defined the cutoff point of 6 months as the proportion of children on any breast milk for at least 12 months was very low which would result in lack of statistical power.

Kaplan-Meier curves estimates were fitted to describe exclusive and any breast milk feeding duration (continuous variable) only among infants who initiated breast milk feeding.

Analyses were performed using STATA 11.0 software (Stata Corporation, College Station, TX, USA).

\subsection{Systematic literature review}

The review was conducted based on the Preferred Reporting of Systematic Reviews and Meta-Analysis (PRISMA) guidelines. ${ }^{13,14}$ PubMed ${ }^{\circledR}$ was searched from inception to January 2017, to identify original published studies reporting the prevalence and/or duration of breast milk feeding in very preterm infants. The following search expression was used [("breast milk" OR breastmilk OR breastfeeding OR feeding OR "human milk") AND ("very preterm" OR "very premature" OR "extreme prematurity" OR "extremely preterm" OR "extremely premature" OR "extreme preterm" OR "very low birth weight" OR "very low birthweight") AND (duration OR prevalence OR frequency OR proportion)], 443 studies were identified.

Retrieved publications were screened by 2 researchers (CR and RT) following predefined criteria to determine eligibility. Studies were excluded if: (1) the full text was not written in English, French, German, Italian, Portuguese, or Spanish; (2) did not involve humans (e.g. in vitro or animal research); (3) non-original articles (e.g. book chapters, review articles, editorials, comments, guidelines); (4) reported qualitative research or case studies; (5) non-observational (e.g. randomized controlled trials); (6) case-control; (7) not focused on very preterm infants ( $\leq 32$ weeks of gestational age) or very low birthweight ( $\leq 1500 \mathrm{~g}$ ); (8) data not related to the prevalence and/or duration of breast milk feeding; and (9) duplicate studies or evaluating the same sample.

Two researchers (CR and RT) evaluated the included studies to extract the following data: year of publication, country, infants' year of birth, sample size, gestational age, and/or birthweight. The prevalence by type of breast milk feeding practices was extracted, also considering the reporting period (e.g. at initiation, at hospital discharge) and/or duration reported, whenever available. Differences in the data extracted by the 2 researchers were discussed involving a third researcher (HB) whenever necessary.

In this review, breast milk feeding practices were categorized as: exclusive breast milk, mixed (breast milk with formula) and any breast milk (receiving some breast milk, independently if it was exclusive or mixed). Breast milk was considered if it was the mother's own milk or a donor's milk and regardless of the feeding method (directly from the breast, bottle, tube, or cup).

\section{3 | RESULTS}

\section{1 | Prevalence and duration of breast milk feeding}

Our sample included $26.4 \%(n=123)$ extremely preterm (<28 weeks) and $73.6 \%(n=343)$ very preterm ( 28 to 31 weeks) infants with a median gestational age of 29 weeks (p25-p75: 27-31). The median birthweight was $1170 \mathrm{~g}$ (p25-p75: 945-1430) and the median length of hospital stay was 51 days (p25-p75: 37-71). Overall, the prevalence of exclusive breast milk feeding initiation was 65.3\% (290/444) and 91.0\% (424/466) for any breast milk feeding. No differences were found between North and LVT on exclusive (63.3\% vs $67.1 \%$ ) or any breast milk feeding ( $89.4 \%$ vs $92.4 \%$ ).

Figure $1 \mathrm{~A}$ shows that $34.7 \%$ of very preterm infants never received breast milk exclusively, $24.8 \%$ were exclusively fed with breast milk for $<2$ months, and $9.9 \%$ for at least 6 months or more. While only $9.3 \%(42 / 453)$ of very preterm infants never received any breast milk, $25.8 \%$ were fed for $<2$ months and $38.4 \%$ between 2 months and $<6$ months. Overall, $26.5 \%$ received any breast milk for 6 months or more, $10.2 \%$ for 12 months or more, and $2.0 \%$ 24 months or more (Figure 1B).

Tables 1 and 2 summarize maternal and infant characteristics according to exclusive and any breast milk feeding duration respectively. No differences were found for exclusive breast milk feeding 
(A) Exclusive breast milk $(n=444)$

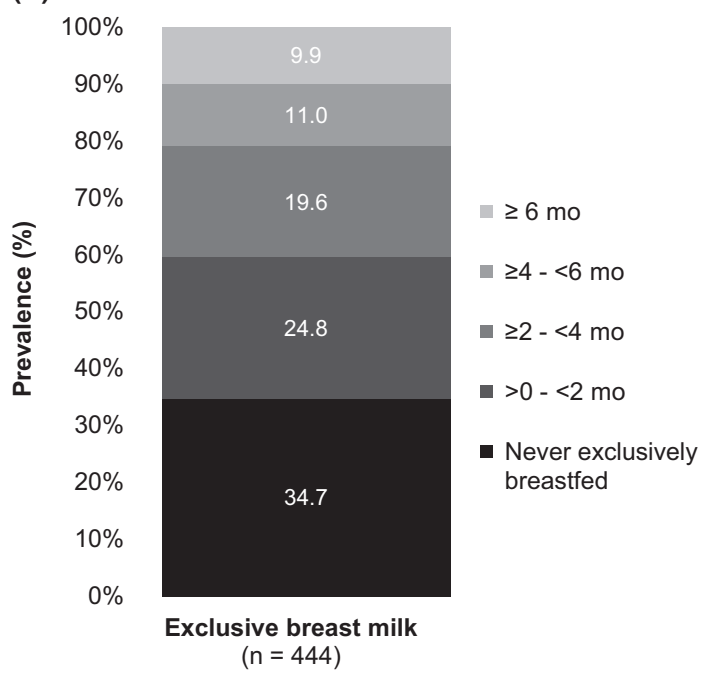

(B) Any breast milk $(n=453)$

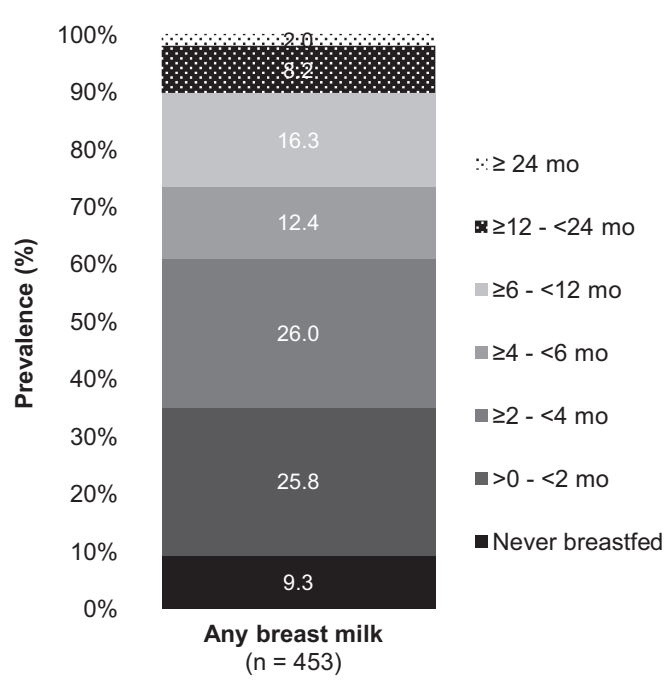

FIGURE 1 A and B, Duration of exclusive breast milk feeding (A) and any breast milk feeding $(B)$ in Portuguese very preterm infants. The duration is reported in months of chronological age.

regarding the maternal and infant characteristics evaluated. We observed that among children who never received any breast milk feeding, $26.2 \%$ were of non-Portuguese mothers and $52.4 \%$ were of multiparae women; of those who received any breast milk for at least 6 months or more, $15.8 \%$ were of non-Portuguese mothers and $36.1 \%$ of multiparae women.

Figure $2 A, B$ present the proportion of very preterm infants remaining on exclusive and any breast milk by month, up to 6 and 12 months, respectively, only among infants who initiated breast milk feeding. The duration of exclusive breast milk feeding ranged from 0.1 to 9.0 months, with a median duration of 2.0 months (p25p75: 1.0-4.0). At 6 months of age $<5 \%$ of children were on exclusive breast milk feeding. Any breast milk feeding duration ranged from 0.1 to 36.0 months, with a median duration of 3.0 months (p25-p75: 1.2-6.0). At the end of the first month, $25 \%$ of children had already
TAB LE 1 Exclusive breast milk feeding duration (chronological age) according to maternal and infant characteristics $(n=444)$

\begin{tabular}{|c|c|c|c|}
\hline \multirow[b]{2}{*}{ Characteristics } & \multicolumn{3}{|c|}{$\begin{array}{l}\text { Exclusive breast milk feeding duration } \\
\text { (chronological age) }\end{array}$} \\
\hline & $\begin{array}{l}\text { Never } \\
(n=154) \\
n(\%)\end{array}$ & $\begin{array}{l}<4 \text { months } \\
(\mathrm{n}=197) \\
\mathrm{n}(\%)\end{array}$ & $\begin{array}{l}\geq 4 \text { months } \\
(n=93) \\
n(\%)\end{array}$ \\
\hline \multicolumn{4}{|c|}{ Maternal age at birth (y) } \\
\hline$\leq 29$ & $49(31.8)$ & $80(40.6)$ & $31(33.3)$ \\
\hline $30-34$ & $54(35.1)$ & $67(34.0)$ & $43(46.2)$ \\
\hline$\geq 35$ & $51(33.1)$ & $50(25.4)$ & $19(20.4)$ \\
\hline Missing & 0 & 0 & 0 \\
\hline \multicolumn{4}{|c|}{ Mothers' country of birth } \\
\hline Portugal & $131(85.1)$ & $179(90.9)$ & $82(88.2)$ \\
\hline Others & $23(14.9)$ & $18(9.1)$ & $11(11.8)$ \\
\hline Missing & 0 & 0 & 0 \\
\hline \multicolumn{4}{|c|}{ Neighbourhood socio-economic deprivation } \\
\hline 1 (least deprived) & $40(26.5)$ & $65(33.0)$ & $33(36.3)$ \\
\hline 2 & $36(23.8)$ & $42(21.3)$ & $16(17.6)$ \\
\hline 3 & $22(14.6)$ & $23(11.7)$ & $14(15.4)$ \\
\hline 4 & $26(17.2)$ & $32(16.2)$ & $18(19.8)$ \\
\hline 5 (most deprived) & $27(17.9)$ & $35(17.8)$ & $10(11.0)$ \\
\hline Missing & $3(1.9)$ & 0 & $2(2.2)$ \\
\hline \multicolumn{4}{|l|}{ Parity } \\
\hline Primipara & $92(59.7)$ & $138(70.0)$ & $61(66.3)$ \\
\hline Multipara & $62(40.3)$ & $59(30.0)$ & 31 (33.7) \\
\hline Missing & 0 & 0 & $1(1.1)$ \\
\hline \multicolumn{4}{|l|}{ Twin } \\
\hline No & $105(68.2)$ & $134(68.0)$ & $65(69.9)$ \\
\hline Yes & $49(31.8)$ & $63(32.0)$ & $28(30.1)$ \\
\hline Missing & 0 & 0 & 0 \\
\hline \multicolumn{4}{|l|}{ Child's gender } \\
\hline Male & $87(56.5)$ & $108(54.8)$ & $57(61.3)$ \\
\hline Female & $67(43.5)$ & $89(45.2)$ & $36(38.7)$ \\
\hline Missing & 0 & 0 & 0 \\
\hline \multicolumn{4}{|c|}{ Gestational age at birth (wk) } \\
\hline $24-27$ & $44(28.6)$ & $51(25.9)$ & $23(24.7)$ \\
\hline $28-29$ & $35(22.7)$ & $61(31.0)$ & $27(29.0)$ \\
\hline $30-31$ & 75 (48.7) & $85(43.2)$ & $43(46.2)$ \\
\hline Missing & 0 & 0 & 0 \\
\hline \multicolumn{4}{|l|}{ Birthweight (g) } \\
\hline$<1000$ & $49(31.8)$ & $73(37.1)$ & $28(30.1)$ \\
\hline$\geq 1000$ & $105(68.2)$ & $124(62.9)$ & 65 (69.9) \\
\hline Missing & 0 & 0 & 0 \\
\hline \multicolumn{4}{|c|}{ Length of hospitalization (d) } \\
\hline Median (p25-p75) & $52(37-71)$ & $52(39-71)$ & $47(34-70)$ \\
\hline Missing & 0 & 0 & 0 \\
\hline
\end{tabular}

p25, percentile 25; p75, percentile 75 . 
TAB LE 2 Any breast milk feeding duration (chronological age) according to maternal and infant characteristics $(n=453)$

\begin{tabular}{|c|c|c|c|}
\hline \multirow[b]{3}{*}{ Characteristics } & \multicolumn{3}{|c|}{$\begin{array}{l}\text { Any breast milk feeding duration } \\
\text { (chronological age) }\end{array}$} \\
\hline & $\begin{array}{l}\text { Never } \\
(n=42)\end{array}$ & $\begin{array}{l}<6 \text { months } \\
(\mathrm{n}=291)\end{array}$ & $\begin{array}{l}\geq 6 \text { months } \\
(n=120)\end{array}$ \\
\hline & n (\%) & $n(\%)$ & $\mathrm{n}(\%)$ \\
\hline \multicolumn{4}{|c|}{ Maternal age at birth $(y)$} \\
\hline$\leq 29$ & $11(26.2)$ & $111(38.1)$ & $38(31.7)$ \\
\hline $30-34$ & $15(35.7)$ & $104(35.7)$ & $50(41.7)$ \\
\hline$\geq 35$ & $16(38.1)$ & $76(26.1)$ & $32(26.7)$ \\
\hline Missing & 0 & 0 & 0 \\
\hline \multicolumn{4}{|c|}{ Mothers' country of birth } \\
\hline Portugal & $31(73.8)$ & $267(91.8)$ & $101(84.2)$ \\
\hline Others & $11(26.2)$ & $24(8.2)$ & $19(15.8)$ \\
\hline Missing & 0 & 0 & 0 \\
\hline \multicolumn{4}{|c|}{ Neighbourhood socio-economic deprivation } \\
\hline 1 (least deprived) & $8(19.0)$ & $97(33.6)$ & 39 (33.3) \\
\hline 2 & $11(26.2)$ & $58(20.1)$ & $26(22.2)$ \\
\hline 3 & $6(14.3)$ & $42(14.5)$ & $14(12.0)$ \\
\hline 4 & $11(26.2)$ & $41(14.2)$ & $24(20.5)$ \\
\hline 5 (most deprived) & $6(14.3)$ & $51(17.6)$ & $14(12.0)$ \\
\hline Missing & 0 & $2(0.7)$ & $3(2.5)$ \\
\hline \multicolumn{4}{|l|}{ Parity } \\
\hline Primipara & $20(47.6)$ & $197(67.7)$ & $76(63.9)$ \\
\hline Multipara & $22(52.4)$ & $94(32.3)$ & $43(36.1)$ \\
\hline Missing & 0 & 0 & $1(0.8)$ \\
\hline \multicolumn{4}{|l|}{ Twin } \\
\hline No & $26(61.9)$ & $196(67.4)$ & $90(75.0)$ \\
\hline Yes & $16(38.1)$ & $95(32.6)$ & $30(25.0)$ \\
\hline Missing & 0 & 0 & 0 \\
\hline \multicolumn{4}{|l|}{ Child's gender } \\
\hline Male & $21(50.0)$ & $165(56.7)$ & $71(59.2)$ \\
\hline Female & $21(50.0)$ & $126(43.3)$ & $49(40.8)$ \\
\hline Missing & 0 & 0 & 0 \\
\hline \multicolumn{4}{|c|}{ Gestational age at birth (wk) } \\
\hline $24-27$ & $14(33.3)$ & $70(24.0)$ & $34(28.3)$ \\
\hline $28-29$ & $10(23.8)$ & $85(29.2)$ & $32(26.7)$ \\
\hline $30-31$ & $18(42.9)$ & $136(46.7)$ & $54(45.0)$ \\
\hline Missing & 0 & 0 & 0 \\
\hline \multicolumn{4}{|l|}{ Birthweight (g) } \\
\hline$<1000$ & $16(38.1)$ & $99(34.0)$ & $37(30.8)$ \\
\hline$\geq 1000$ & $26(61.9)$ & $192(66.0)$ & $83(69.2)$ \\
\hline Missing & 0 & 0 & 0 \\
\hline \multicolumn{4}{|c|}{ Length of hospitalization (d) } \\
\hline Median (p25-p75) & $\begin{array}{l}56.5 \\
(39-88)\end{array}$ & $52(37-70)$ & $\begin{array}{l}47.5 \\
(36-70)\end{array}$ \\
\hline Missing & 0 & 0 & 0 \\
\hline
\end{tabular}

p25, percentile 25; p75, percentile 75 . stopped any breast milk feeding. At 12 months of age $<10.0 \%$ of children received any breast milk and at 18 months $<3 \%$. In $34.4 \%$ of the cases, breast milk feeding stopped during hospital stay.

\section{2 | Systematic literature review}

From the literature review, we identified 31 studies $^{4,6,15-43}$ that address the prevalence and/or duration of breast milk feeding in very preterm infants (Table S2), reporting data from 34 different countries (1 study was multicenter): 16 European, 11 American, 3 Oceanian, 3 Asian, and 1 African. Articles were published between 1998 and 2016, and described data collected between 1986 and 2015. Among the 31 studies included, 11 reported the prevalence of breast milk feeding at initiation, 13 at hospital discharge, 9 at some other time (e.g. in the first 2 weeks after birth, at 36 weeks postmenstrual age), and 13 presented complete data on overall duration. Only 9 studies $^{6,18,21,28,35,36,39,41,42}$ presented data for breast milk feeding specifically at 6 months or more (chronological or corrected age) and 2 studies $^{6,36}$ at 12 months (chronological age) (Table 3). The prevalence of any breast milk feeding at 6 months or more (chronological or corrected age) ranged from $19.9 \%$ in Israel $^{18}$ to $50.0 \%$ in Denmark, ${ }^{6}$ and for exclusive breast milk ranged between $1.0 \%$ in Sweden ${ }^{28}$ and $27.0 \%$ in Denmark. ${ }^{6}$ At 12 months, the prevalence of any breast milk was $8.0 \%$ in Denmark ${ }^{6}$ and $12.0 \%$ in Sweden, ${ }^{36}$ the only studies reporting this information. None of the studies presented data for breast milk feeding duration for more than 12 months.

\section{4 | COMMENT}

\section{1 | Principal findings}

This is the first description of the duration of breast milk feeding in Portuguese very preterm infants. We found that $91.0 \%$ of the very preterm infants initiated any breast milk feeding and $65.3 \%$ exclusive breast milk feeding. The median duration of exclusive breast milk feeding was 2 months and of any breast milk feeding 3 months. The World Health Organization (WHO) recommends 6 months of exclusive breast milk with continued breast milk feeding along with complementary foods up to 2 years of age or beyond. ${ }^{1,2}$ In Portugal, very preterm infants are clearly far from achieving this recommendation, despite high initiation rates for any breast milk feeding.

\section{2 | Interpretation}

In Generation XXI, a population-based Portuguese birth cohort, including live births with at least 24 weeks of gestation, and assembled in 2005/2006 in the metropolitan area of Porto, the proportion of infants that never received breast milk was similar to the observed in our very preterm sample (8.4\% vs $9.0 \%) .{ }^{44}$ The median durations of exclusive and any breast milk feeding in our study were shorter than in infants from the Generation XXI cohort, 2.0 vs 2.5 months for exclusive and 3.0 vs 5.5 months for any breast milk feeding, respectively. ${ }^{44}$ In 2013 , the prevalence of any breast milk feeding 
(A) Exclusive breast milk $(n=290)$

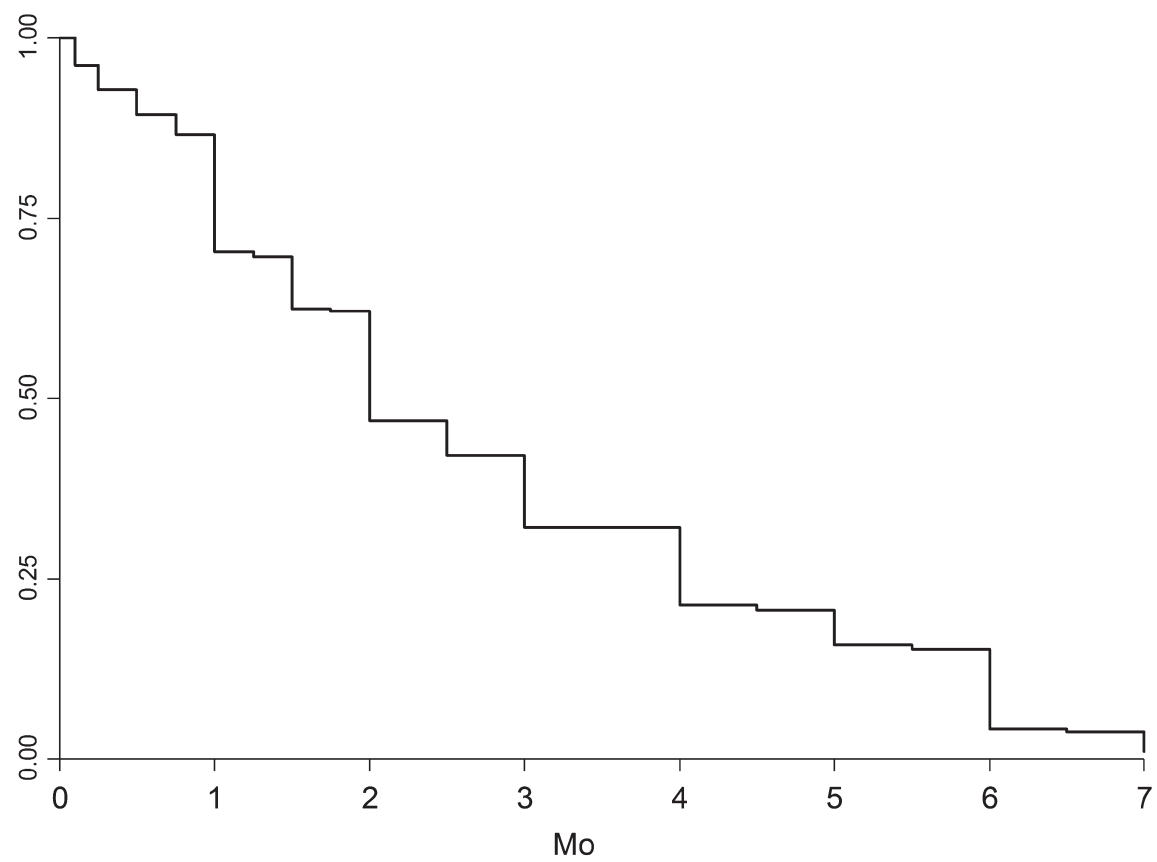

(B) Any breast milk $(n=411)$

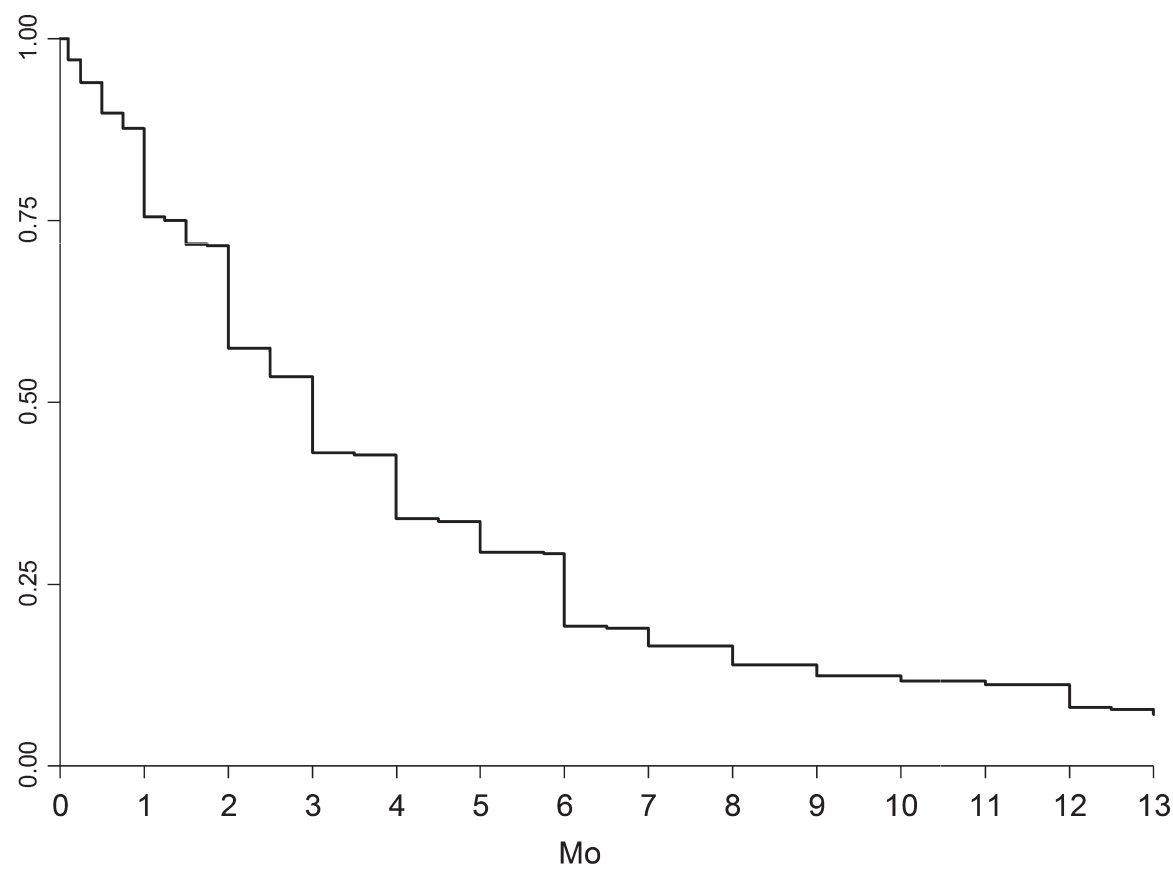

FIGURE 2 A and B, Kaplan-Meier curve with estimates of exclusive breast milk feeding duration (A) and of any breast milk feeding duration $(B)$ in very preterm infants in Portugal, only among infants who initiated the type of breast milk feeding considered. The duration is reported in months of chronological age. in the North region of Portugal was $96.7 \%$ in very preterm infants evaluated at $15-22$ days after delivery and $96.4 \%$ in full-term infants analysed during the puerperium. ${ }^{7}$

Few studies reported breast milk feeding prevalence and duration in very preterm infants, and most of them described the prevalence at initiation, during hospitalization, and/or at discharge, as revealed our systematic literature review. In addition, we observed that the prevalence and duration of breast milk feeding in very preterm infants varies widely across countries. At initiation period, the prevalence of any breast milk feeding in very preterm infants was $99.0 \%$ in Denmark
(2009/2010), ${ }^{6} 96.8 \%$ in Australia (2011/2012), ${ }^{21}$ and $75.5 \%$ in the USA (2007-2010). ${ }^{20}$ The Australian study showed that the proportion of very preterm infants that received breast milk for more than 6 months was $41.7 \%,{ }^{21}$ while it was only $26.5 \%$ at 6 months or more in our sample. Similarly, in Denmark and Sweden, $50.0 \%$ and $45.0 \%$ of very preterm infants were being fed with breast milk at 6 months of age respectively. ${ }^{6,36}$ At hospital discharge, results from a populationbased study of very preterm infants born in 2003 in 8 European regions showed the prevalence of any breast milk feeding at discharge ranged between 19\% in Burgundy (France) and 70\% in Lazio (Italy), 


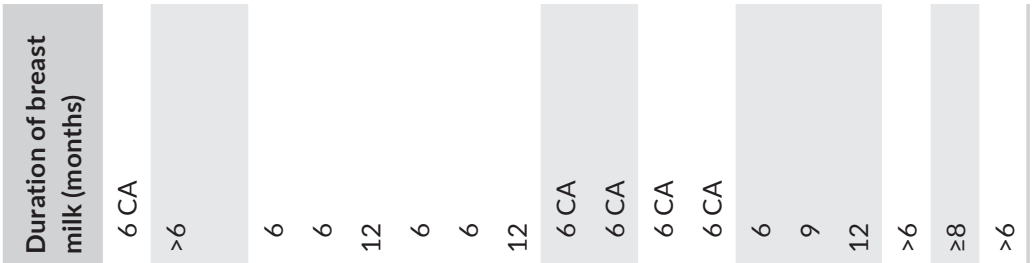

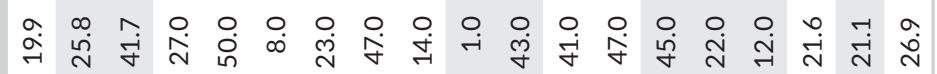

$$
\frac{1}{2}
$$

$$
\text { o }
$$

a


while $50 \%$ of participating Portuguese very preterm were fed with any breast milk at discharge (6\% exclusive and $44 \%$ mixed). ${ }^{4}$ This review did not find any study reporting data on breast milk feeding after 12 months in very preterm infants. Furthermore, there is a paucity of data from Southern and Eastern Europe countries.

The low prevalence and short duration of breast milk feeding among very preterm infants may be explained by several factors. First, by difficulties inherent to their higher neonatal morbidity, such as the delicate transition from enteral to oral feeding and the long stay in the stressful environment of the NICUs. ${ }^{18,32}$ In addition, factors related to health care services may play an important role in the support and promotion of breast milk feeding as it has been shown that hospital policies and practices, independently of maternal sociodemographic factors, exert influence on the initiation and duration of breast milk feeding. ${ }^{45}$ A previous study of the Portuguese infants in the EPICE cohort found a wide variation in the prevalence of breast milk feeding at discharge across Portuguese NICUs, ranging from $49.0 \%$ to $83.4 \%$ for any breast milk and from $3.3 \%$ to $50.0 \%$ for exclusive breast milk. This study found that NICUs characteristics, as having designated members to support mothers who were breast feeding, influence feeding practices independently of maternal and infant characteristics. ${ }^{46}$ Furthermore, an inadequate legislation covering maternity protection may hinder women to breastfeed their child. ${ }^{47}$ In Portugal, mothers have access to 4 months of fully paid parental leave, which is shorter than the WHO recommendation for exclusive breast milk feeding. Considering that the association between early return to work and shorter breast milk feeding duration has been reported in several studies, this may partially explain the differences between countries described here, as Sweden, Australia, and Denmark provide longer periods of maternity leave than Portugal. ${ }^{48}$ Overall, our findings indicate a need for improvements in breast milk feeding supportive measures for mothers at neonatal units and after discharge. ${ }^{21,49}$

\subsection{Strengths of the study}

A major strength of our study is the use of high-quality data, obtained from a population-based prospective cohort, using a structured questionnaire at 3 years of age. This allowed us to estimate the prevalence and total duration of exclusive and any breast milk feeding until the age of 3 . In addition, our study also included a systematic review, and to the best of our knowledge, this is the first systematic review describing the prevalence and/or duration of breast milk feeding in very preterm infants.

\subsection{Limitations of the data}

Our results could be affected by potential recall bias due to retrospective data collection, and the time between stopping breast milk feeding and reporting for most parents. In a birth cohort from Denmark, comparing data on breast milk feeding obtained from the self-administered questionnaire at 18 months with the weekly short message service (SMS) questions since birth, a longer duration of exclusive breast milk feeding using the self-administered questionnaire was observed, while the duration of any breast milk feeding was similar between the 2 methods. ${ }^{50}$ In a Brazilian study, $70 \%$ of mothers correctly recalled breast milk feeding duration when their children were 4 years of age, while $21 \%$ reported higher duration and $9 \%$ reported lower duration. ${ }^{51}$

Another limitation was the lack of detailed information on sociodemographic characteristics, such as mother's employment and educational level. However, we georeferenced the infants and used the European Deprivation Index to classify neighbourhood socioeconomic deprivation index, which has been used as a valid proxy of individual socio-economic position, ${ }^{11}$ and we did not find differences. This result was unexpected considering that previous studies have shown that maternal socio-economic status is associated with initiation and duration of breast milk feeding in very preterm infants. ${ }^{31,36}$ However, the European Deprivation Index is a validated and robust measure with very fine geographical scales and was used in other studies with Portuguese data that reported associations with different outcomes. ${ }^{52,53}$

Regarding our systematic literature review, a considerable heterogeneity was observed across the studies, not allowing us to conduct a meta-analysis. It is difficult to compare the findings of studies on breast milk feeding prevalence due to the different definitions of breast milk feeding used-only breast feeding or breast and bottle feeding; the misclassification of exclusive breast milk feeding; the different periods of assessment-during hospital stay, at or after hospital discharge; and the use of chronological/corrected age when reporting the duration. In this sense, the comparisons among studies should be performed carefully.

\section{5 | CONCLUSIONS}

Given that the duration of both exclusive and any breast milk feeding is positively associated with several optimal health outcomes and, as we found that in Portugal both were below the recommendations, more studies are needed to clarify the longitudinal obstacles to breast milk feeding beyond hospital discharge. Appropriate interventions are needed to increase both the prevalence and duration of exclusive and any breast milk feeding among this vulnerable population. Hence, enabling women to remain at home with their infants for a longer period through a more comprehensive labour policy and maternity leave provision (e.g. to establish 6 months mandatory paid maternity leave) represent public health measures that can contribute to improve breast milk feeding practices in Portugal. ${ }^{47}$

\section{ACKNOWLEDGEMENTS}

The authors are grateful to the parents and infants enrolled in the EPICE-Portugal cohort, and acknowledge all members of the research team and all members of the staff in the Departments of Obstetrics and Neonatology from the participating hospitals. 
The authors thank Ana Isabel Ribeiro for her collaboration in georeferencing the infants and for computing the neighbourhood socio-economic deprivation index.

\section{ORCID}

Carina Rodrigues (iD http://orcid.org/0000-0003-1720-2808

Raquel Teixeira iD http://orcid.org/0000-0003-1942-8317

Maria João Fonseca (iD http://orcid.org/0000-0003-0566-3455

Jennifer Zeitlin (iD http://orcid.org/0000-0002-9568-2969

Henrique Barros (iD http://orcid.org/0000-0003-4699-6571

\section{REFERENCES}

1. Kramer M, Kakuma R. Optimal duration of exclusive breastfeeding (Review). Cochrane Database Syst Rev. 2012;8:CD003517.

2. Edmond K, Bahl R. Optimal Feeding of Low-Birth-Weight Infants: Technical Review. Geneva: World Health Organization; 2006. [13th April 2017] http://whqlibdoc.who.int/publications/2006/9789241595094_eng. pdf?ua=1.

3. Beaino G, Khoshnood B, Kaminski M, et al. Predictors of the risk of cognitive deficiency in very preterm infants: the EPIPAGE prospective cohort. Acta Paediatr. 2011;100:370-378.

4. Bonet M, Blondel B, Agostino R, et al. Variations in breastfeeding rates for very preterm infants between regions and neonatal units in Europe: results from the MOSAIC cohort. Arch Dis Child Fetal Neonatal Ed. 2011;96:F450-F452.

5. Flacking R, Nyqvist $\mathrm{KH}$, Ewald U. Effects of socioeconomic status on breastfeeding duration in mothers of preterm and term infants. Eur J Public Health. 2007;17:579-584.

6. Maastrup R, Hansen BM, Kronborg $\mathrm{H}$, et al. Breastfeeding progression in preterm infants is influenced by factors in infants, mothers and clinical practice: the results of a national cohort study with high breastfeeding initiation rates. PLoS ONE. 2014;9:e108208.

7. Alves E, Magano R, Amorim M, Silva S. Aleitamento materno de crianças muito pré-termo e de crianças de termo em contexto hospitalar. Arq Med. 2015;29:135-137.

8. Zeitlin J, Manktelow BN, Piedvache A, et al. Use of evidence based practices to improve survival without severe morbidity for very preterm infants: results from the EPICE population based cohort. BMJ. 2016;354:i2976.

9. Statistics Portugal. Live births in Portugal. Statistics Portugal; 2016 [19th July 2016]; http://www.ine.pt

10. Barros H, Rodrigues C, Costa R, et al. Effective Perinatal Intensive Care in Europe (EPICE): descrição do projeto e primeiros resultados em Portugal. Arq Med. 2014;28:183-190.

11. Guillaume E, Pornet C, Dejardin O, et al. Development of a crosscultural deprivation index in five European countries. J Epidemiol Community Health. 2016;70:493-499.

12. Ribeiro Al, Mayer A, Miranda A, Pina MF. The Portuguese version of the European deprivation index: an instrument to study health inequalities. Acta Med Port. 2017;30:17-25.

13. Liberati A, Altman DG, Tetzlaff J, et al. The PRISMA statement for reporting systematic reviews and meta-analyses of studies that evaluate health care interventions: explanation and elaboration. PLoS Med. 2009;6:e1000100.

14. Moher D, Shamseer L, Clarke M, et al. Preferred reporting items for systematic review and meta-analysis protocols (PRISMA-P) 2015 statement. Syst Rev. 2015;4:1.

15. Ericson J, Flacking R, Hellström-Westas L, Eriksson M. Changes in the prevalence of breast feeding in preterm infants discharged from neonatal units: a register study over 10 years. BMJ Open. 2016;6:e012900.

16. Freitas BAC, Lima LM, Carlos CFLV, Priore SE, Franceschini SCC. Duration of breastfeeding in preterm infants followed at a secondary referral service. Rev Paul Pediatr. 2016;34:189-196.

17. Herich LC, Cuttini M, Croci I, et al. Maternal education is associated with disparities in breastfeeding at time of discharge but not at initiation of enteral feeding in the neonatal intensive care unit. $J$ Pediatr. 2016;182:59-65. e57.

18. Morag I, Harel T, Leibovitch L, Simchen MJ, Maayan-Metzger A, Strauss T. Factors associated with breast milk feeding of very preterm infants from birth to 6 months corrected age. Breastfeed Med. 2016;11:138-143.

19. Casavant SG, McGrath JM, Burke G, Briere C-E. Caregiving factors affecting breastfeeding duration within a neonatal intensive care unit. Adv Neonatal Care. 2015;15:421-428.

20. Hwang S, Lu E, Cui X, Diop H, Barfield W, Manning S. Home care practices for preterm and term infants after hospital discharge in Massachusetts, 2007 to 2010. J Perinatol. 2015;35:880-884.

21. Sharp M, Campbell C, Chiffings D, Simmer K, French N. Improvement in long-term breastfeeding for very preterm infants. Breastfeed Med. 2015;10:145-149.

22. Wilson E, Christensson K, Brandt L, Altman M, Bonamy A-K. Early provision of mother's own milk and other predictors of successful breast milk feeding after very preterm birth: a regional observational study. J Hum Lact. 2015;31:393-400.

23. Murase M, Nommsen-Rivers L, Morrow AL, et al. Predictors of low milk volume among mothers who delivered preterm. J Hum Lact. 2014;30:425-435.

24. Barois J, Grognet S, Tourneux P, Leke A. Maternal and neonatal factors associated with successful breastfeeding in very preterm infants. Arch Pediatr. 2013;20:969-973.

25. Davanzo R, Monasta L, Ronfani L, Brovedani P, Demarini S. Breastfeeding at NICU discharge: a multicenter Italian study. J Hum Lact. 2013;29:374-380.

26. Corpeleijn WE, Kouwenhoven SM, Paap MC, et al. Intake of own mother's milk during the first days of life is associated with decreased morbidity and mortality in very low birth weight infants during the first 60 days of life. Neonatology. 2012;102: 276-281.

27. Maayan-Metzger A, Avivi S, Schushan-Eisen I, Kuint J. Human milk versus formula feeding among preterm infants: short-term outcomes. Am J Perinatol. 2012;29:121.

28. Flacking R, Ewald U, Wallin L. Positive effect of kangaroo mother care on long-term breastfeeding in very preterm infants. J Obstet Gynecol Neonatal Nurs. 2011;40:190-197.

29. Maia $C$, Brandão R, Roncalli Â, Maranhão H. Length of stay in a neonatal intensive care unit and its association with low rates of exclusive breastfeeding in very low birth weight infants. J Matern Fetal Neonatal Med. 2011;24:774-777.

30. Pineda R. Predictors of breastfeeding and breastmilk feeding among very low birth weight infants. Breastfeed Med. 2011;6: 15-19.

31. Zachariassen G, Faerk J, Grytter C, Esberg B, Juvonen P, Halken S. Factors associated with successful establishment of breastfeeding in very preterm infants. Acta Paediatr. 2010;99:1000-1004.

32. Kirchner L, Jeitler V, Waldhör T, Pollak A, Wald M. Long hospitalization is the most important risk factor for early weaning from breast milk in premature babies. Acta Paediatr. 2009;98: 981-984.

33. Lee HC, Gould JB. Factors influencing breast milk versus formula feeding at discharge for very low birth weight infants in California. J Pediatr. 2009;155:657-662. e652.

34. Sisk PM, Lovelady CA, Dillard RG, Gruber KJ, O'Shea TM. Maternal and infant characteristics associated with human milk 
feeding in very low birth weight infants. J Hum Lact. 2009;25: 412-419.

35. Åkerström S, Asplund I, Norman M. Successful breastfeeding after discharge of preterm and sick newborn infants. Acta Paediatr. 2007;96:1450-1454.

36. Flacking R, Wallin L, Ewald U. Perinatal and socioeconomic determinants of breastfeeding duration in very preterm infants. Acta Paediatr. 2007;96:1126-1130.

37. Were F, Bwibo NO. Neonatal nutrition and later outcomes of very low birth weight infants at Kenyatta national hospital. Afr Health Sci. 2007;7:108-114.

38. Merewood A, Brooks D, Bauchner H, MacAuley L, Mehta SD. Maternal birthplace and breastfeeding initiation among term and preterm infants: a statewide assessment for Massachusetts. Pediatrics. 2006;118:e1048-e1054.

39. Smith MM, Durkin M, Hinton VJ, Bellinger D, Kuhn L. Initiation of breastfeeding among mothers of very low birth weight infants. Pediatrics. 2003;111:1337-1342.

40. Furman L, Minich N, Hack M. Correlates of lactation in mothers of very low birth weight infants. Pediatrics. 2002;109:e57.

41. Horwood L, Darlow B, Mogridge N. Breast milk feeding and cognitive ability at 7-8 years. Arch Dis Child Fetal Neonatal Ed. 2001;84:F23-F27.

42. Elder D, Hagan R, Evans S, Benninger H, French N. Hospital admissions in the first year of life in very preterm infants. J Paediatr Child Health. 1999;35:145-150.

43. Hylander MA, Strobino DM, Dhanireddy R. Human milk feedings and infection among very low birth weight infants. Pediatrics. 1998;102:e38.

44. Moreira DMF. Effect of breastfeeding on child and material adiposity 4-5 years after birth: results from the Portuguese birth cohort. University of Porto; 2013.

45. Manganaro R, Marseglia L, Mamì C, et al. Effects of hospital policies and practices on initiation and duration of breastfeeding. Child Care Health Dev. 2009;35:106-111.

46. Rodrigues $C$, Severo $M$, Zeitlin J, Barros $H$, on behalf of the Portuguese EPICE (Effective Perinatal Intensive Care in Europe) Network. The Type of Feeding at Discharge of Very Preterm Infants: Neonatal Intensive Care Units Policies and Practices Make a Difference. Breastfeed Med. 2018;13:50-59.

\section{APPENDIX}

\section{Members of the EPICE-Portugal Network}

Adelina Sá Couto, Aldina Lopes, Alexandra Almeida, Alexandrina Portela, Alice Vilas Boas, Almerinda Pereira, Ana Aroso, Ana Berdeja, Ana Bettencourt, Ana Campos, Ana Castilho Santos, Ana Isabel Machado, Ana Maria Andrade, Ana Melo Bento, Ana Neto, Ana Pita, Ana Rute Ferreira, Angelina Tavares, Anselmo Costa, Antónia Nazaré, António Braga, António Fonseca, António Lanhoso, António Vilarinho, Beatriz Sousa, Carla Sá, Carlos Moniz, Cármen Carvalho, Catarina Dâmaso, Célia Araújo, Clara Paz Dias, Cláudia Araújo, Conceição Casanova, Conceição Cunha, Conceição Faria Murinello, Conceição Telhado, Cristina Didelet, Cristina Leite, Cristina Martins, Cristina Trindade, Daniela Almeida, Domingos Jardim da Pena, Dulce Oliveira, Eduarda Reis, Eduardo Fernandes, Ester Casal, Eurico Gaspar, Fátima Fonseca, Fátima Romão, Fernanda Matos, Fernando Cirurgião, Filomena Nunes, Gabriela Pereira, Glória Carvalhosa, Graça Henriques, Gustavo Rodrigues, Helena Almeida, Helena Oliveira, Helena Sousa, Hercília Guimarães,
47. Rollins NC, Bhandari N, Hajeebhoy N, et al. Why invest, and what it will take to improve breastfeeding practices? Lancet. 2016;387:491-504.

48. Scott JA, Binns CW, Oddy WH, Graham KI. Predictors of breastfeeding duration: evidence from a cohort study. Pediatrics. 2006;117:e646-e655.

49. Ross ES, Browne JV. Feeding outcomes in preterm infants after discharge from the Neonatal Intensive Care Unit (NICU): a systematic review. Newborn Infant Nurs Rev. 2013;13:87-93.

50. Bruun S, Buhl S, Husby S, et al. Breastfeeding, infant formula, and introduction to complementary foods-comparing data obtained by questionnaires and health visitors' reports to weekly short message service text messages. Breastfeed Med. 2017;12:554-560.

51. Huttly SR, Barros FC, Victora CG, Beria JU, Vaughan JP. Do mothers overestimate breast feeding duration? An example of recall bias from a study in southern Brazil. Am J Epidemiol. 1990;132:572-575.

52. Ribeiro Al, Krainski ET, Autran R, Teixeira H, Carvalho MS, de Pina MF. The influence of socioeconomic, biogeophysical and built environment on old-age survival in a Southern European city. Health Place. 2016;41:100-109.

53. Hoffimann E, Barros H, Ribeiro Al. Socioeconomic inequalities in green space quality and accessibility-evidence from a Southern European city. Int J Environ Res Public Health. 2017;14:916.

\section{SUPPORTING INFORMATION}

Additional Supporting Information may be found online in the supporting information tab for this article.

How to cite this article: Rodrigues C, Teixeira R, Fonseca MJ, Zeitlin J, Barros H; on behalf of the Portuguese EPICE (Effective Perinatal Intensive Care in Europe) Network. Prevalence and duration of breast milk feeding in very preterm infants: A 3-year follow-up study and a systematic literature review. Paediatr Perinat Epidemiol. 2018;00:1-10. https://doi.org/10.1111/ppe.12457

Ilídio Quelhas, Isabel Canelas, Isabel Carolino Silva, Isabel Knoch, Isabel Martins, Jacinto Torres, Joana Saldanha, Joana Sampaio, João Mendes, Joaquim Marinho, Joaquina Baltazar, Jorge Ribeiro, Jorge Silva, José Amorim, José Furtado, José Guimarães, José Luís Fonseca, José Miguel Nogueira, José Oliveira, José Pombeiro, José Teixeira, Juan Calviño, Judite Marques, Lucília Araújo, Luís Caturra, Luís Graça, Maria do Carmo Serra, Maria do Céu Machado, Maria Paula Arteaga, Margarida Cabral, Margarida Pontes, Margarida Seabra, Maria Lurdes Pinho, Maria José Carneiro, Mário Furtado, Mário Paiva, Marisa Cabanas, Marta Aguiar, Marta Barbosa, Micaela Serelha, Nuno Montenegro, Olímpia do Carmo, Óscar Vaz, Osvaldo Soares, Paula Costa, Paula Pinheiro, Paula Soares, Pedro Rocha, Pedro Silva, Pedro Tiago, Raquel Maciel, Ricardo Mira, Rosa Rodrigues, Rosalina Barroso, Rosalinda Rodrigues, Rubina Mendonça, Rui Carrapato, Rui Costa, Rui Pinto, Sara Noéme Prado, Susana Gama de Sousa, Teresa Oliveira, Teresa Rodrigues, Teresa Teles, Teresa Tomé, Teresa Ventura, Valdemar Martins, Vítor Neves, Zélia Nunes. 